\title{
PENGARUH YOGA KEHAMILAN DENGAN KECEMASAN DAN LAMA PERSALINAN KALA I DI KOTA PEKANBARU
}

\author{
Eva Santi Hutasoit ${ }^{1}$, Susani Hayati ${ }^{2}$ \\ PSD III Kebidanan STIKes Payung Negeri Pekanbaru \\ Jalan Tantama no 6 Labuh Baru Pekanbaru \\ Email : eva_santi79@yahoo.com, havatisusani@gmail.com
}

Kata Kunci :

Yoga, Kehamilan, Lama Persalinan

\begin{abstract}
ABSTRAK : Masa kehamilan membuat wanita banyak mengalami perubahan. Perubahan pada tubuh dan pikiran dapat menyebabkan ketidaknyaman pada ibu hamil. Selain ketidaknyamanan fisik yang dirasakan, ketidaknyamanan psikologis juga sering terjadi. Masalah dengan prevalensi yang sering terjadi diantaranya kecemasan dan depresi pada kehamilan. Salah satu intervensi yang dapat mengurangi kecemasan dapat dilakukan latihan fisik seperti yoga. Manfaat yang didapatkan dari yoga antara lain memberikan rasa nyaman, stress menurun, nyeri persalinan berkurang, self efficacy pada persalinan, kualitas hidup meningkat, hubungan interpersonal, fungsi sistem saraf otonom, dan durasi persalinan menjadi singkat. Tujuan penelitian ini adalah untuk menganalisis pengaruh yoga kehamilan terhadap kecemasan dan lama persalinan kala I pada ibu bersalin di kota Pekanbaru. Desain penelitian case control dengan pendekatan studi observasional. Penelitian dilakukan di 5 Rumah Bersalin di Kota Pekanbaru dengan sampel 96 responden. Pengumpulan data menggunakan kuesioner Zung-Self Rating Scale (ZSRS) dan lama persalinan kala I. Analisa Data Bivariat menggunakan perhitungan chi-square. Hasil uji statistik Chi-square variabel kecemasan menunjukkan nilai $p$ value $0,000<0,05$ (CI 95\%), terdapat hubungan antara status kecemasan dengan senam yoga kehamilan. Variabel lama persalinan Kala I menunjukkan nilai $p$ value $0,013<0,05$ (CI 95\%), ada hubungan antara lama kala I persalinan dengan senam yoga kehamilan. Pengaruh senam yoga dapat mengurangi tingkat kecemasan dan memperpendek kala I fase aktif persalinan. Diharapkan kepada petugas kesehatan khususnya bidan agar dapat meningkatkan frekuensi pemberian informasi tentang yoga kehamilan dan frekuensi pelaksanaan kelas senam yoga, baik di RB maupun fasilitas kesehatan lainnya.
\end{abstract}

Key words : Yoga, Pregnancy, Duration of Labor

\section{Info Artikel}

Tanggal dikirim:30-9-2020

Tanggal direvisi:2-11-2020

Tanggal diterima: 5-1-2021

DOI Artikel:

10.36341/jomis.v5i1.1494

Creative Commons

Attribution-

$\underline{\text { NonCommercial-ShareAlike }}$ 4.0 International License.

\begin{abstract}
:
The period of pregnancy makes women experience many changes. Changes in the body and mind can cause discomfort to pregnant women. Apart from physical discomfort, psychological discomfort is also a frequent occurrence. Problems with a high prevalence include anxiety and depression in pregnancy. One of the interventions that can reduce anxiety can be physical exercise such as yoga. The benefits obtained from yoga include providing a sense of comfort, decreased stress, reduced labor pain, self-efficacy in childbirth, increased quality of life, interpersonal relationships, autonomic nervous system function, and shorter duration of labor. The purpose of this study was to analyze the effect of pregnancy yoga on anxiety and the duration of the first stage of labor in the city of Pekanbaru. Case control research design with observational study approach. The study was conducted in 5 maternity homes in Pekanbaru City with a sample of 96 respondents. The data were collected using the Zung-Self Rating Scale (ZSRS) questionnaire and the first stage of labor. Bivariate data analysis used chi-square calculations. The results of the Chi-square statistical test for the anxiety variable showed a $p$ value of $0.000<0.05(95 \% \mathrm{CI})$, there was a relationship between anxiety status and pregnancy yoga exercises. The variable of the first stage of labor showed a p value of $0.013<0.05(95 \% \mathrm{CI})$, there was a relationship between the first stage of labor and pregnancy yoga exercises. The effect of yoga exercises can reduce anxiety levels and shorten the first stage of the active phase of labor. It is hoped that health workers, especially midwives, can increase the frequency of providing information about pregnancy yoga and the frequency of implementing yoga exercise classes, both at RB and other health facilities.
\end{abstract}




\section{PENDAHULUAN}

Kehamilan adalah peristiwa dan proses yang sangat unik, perubahan yang dialami tidak ada yang sama persis antara satu wanita dengan wanita yang lain. Perubahan pada tubuh dan pikiran dapat menyebabkan ketidaknyaman pada ibu hamil. Selain ketidaknyamanan fisik yang dirasakan, ketidaknyamanan psikologis juga sering terjadi [1]. Masalah dengan prevalensi yang sering terjadi diantaranya kecemasan dan depresi pada kehamilan yaitu sekitar 12,5-42\%. Kejadian kecemasan dan depresi pada persalinan sekitar lebih dari $20 \%$ di negara berkembang sedangkan di negara maju sekitar 7-20\%. Selama kehamilan, ibu akan merasakan Kecemasan yang berbeda, dimana kecemasan pada trimester 1 dan 2 lebih rendah dibanding trimester 3 [2] Perencanaan yang matang selama masa kehamilan dapat mengatasi masalah dengan pendekatan yang berkualitas. Salah satu cara latihan fisik yang dapat dilakukan adalah yoga kehamilan. Selain dapat menunjang kelancaran proses kehamilan dan kelahiran, latihan senam yoga juga dapat menjadi salah satu solusi dan sarana untuk belajar secara berkelompok tentang kesehatan ibu hamil secara langsung dengan tujuan meningkatkan pengetahuan, sikap dan keterampilan tentang kehamilan, persalinan, perawatan nifas dan bayi baru lahir [3]

Yoga merupakan olah fisik, mental dan pikiran yang dapat membantu persendian ibu hamil menjadi lentur dan pikiran menjadi tenang terutama pada kehamilan trimester III. Yoga tidak hanya bermanfaat pada kebugaran fisik, tetapi juga mental karena latihan yoga mengajarkan cara bernafas dalam secara sadar dan rileks. Latihan ini akan membantu ibu hamil mengahadapi persalinan. Latihan yoga yang

dikombinasikan dengan latihan kardiovaskular (seperti berjalan) dapat menjadi cara yang ideal bagi ibu hamil agar tetap bugar [3]. Yoga sangat bermanfaat antara lain memberikan rasa nyaman, stress menurun, nyeri persalinan berkurang, efikasi diri pada persalinan dan kualitas hidup meningkat, hubungan interpersonal, fungsi sistem saraf otonom, dan durasi persalinan menjadi singkat [4].

Rumah Bersalin dikota Pekanbaru berjumlah 64 Rumah Bersalin (RB), terdapat 5 RB yang aktif melakukan Senam Yoga Kehamilan. Data ibu hamil yang mengikuti senam ibu hamil adalah RB Dince 14 orang, RB Islah 8 orang, RB Zulfi 11 orang, RB Rosita 12 orang dan RB Yossi 6 orang. Tujuan penelitian ini untuk menganalisis pengaruh yoga kehamilan terhadap kecemasan dan lama persalinan kala I pada ibu bersalin di kota Pekanbaru. State of the art penelitian ini diambil dari beberapa contoh penelitian terdahulu sebagai panduan ataupun contoh untuk penelitian yang dilakukan saat ini untuk melihat fenomena dan hasil survey. Jurnal-jurnal yang berkaitan dengan penelitian membahas 1 variabel independent seperti hubungan prenatal yoga dengan kecemasan atau hubungan prenatal yoga dengan lama persalinan kala I, sehingga pada penelitian ini dilakukan penelitian 2 variabel indenpenden sekaligus. Ada perbedaan teori dengan praktik sehingga dilakukan percobaan intervensi yoga kehamilan. Setelah itu dilakukan pengumpulan data menggunakan kuesioner untuk mengukur ada pengaruh atau tidak ada pengaruh prenatal yoga terhadap kecemasan dan lama persalinan kala I pada ibu bersalin. Setelah itu dilakukan analisis data dan menarik kesimpulan.

\section{TINJAUAN PUSTAKA}

Penelitian Mulyati dan Zafariyana (2018), tentang pengaruh prenatal yoga pada ibu primigravida trimeseter 3 terhadap kecemasan persalinan didapatkan hasil uji pengaruh (uji wilcoxon) p-value sebesar $0,000<0,05$, artinya prenatal yoga berpengaruh terhadap kecemasan dalam menghadapi persalinan. Prenatal yoga 
sangat bermanfaat untuk mengurangi kecemasan yang dialami oleh ibu hamil dalam menghadapi persalinan. Hal ini sesuai dengan hasil penelitian bahwa hasil uji pengaruh didapatkan ada pengaruh prenatal yoga terhadap penurunan kecemasan dalam menghadapi persalinan [5].

Penelitian Devi dkk (2017) di BPM Restu Depok tentang pengaruh yoga prenatal dan hypnobirthing terhadap proses persalinan kala I pada ibu bersalin yang menunjukkan hasil uji statistik mann-whitney dengan nilai $(p$-value $=0,000)$ terdapat pengaruh yoga prenatal dengan proses persalinan kala I. Kesimpulan penelitian ini yaitu yoga prenatal mempengaruhi proses persalinan kala I pada ibu bersalin [6]

\section{METODE}

Penelitian ini menggunakan desain penelitian case control dengan pendekatan studi observasional. Pada penelitian terdapat kelompok ibu bersalin yang telah melakukan senam yoga kehamilan minimal 8 kali dan kelompok ibu bersalin yang tidak melakukan senam yoga kehamilan. Kelompok ibu hamil yang melakukan yoga kehamilan adalah ibu hamil trimester 3 yang sudah dilatih oleh instruktur dan kelompok ini sudah ada sebelum penelitian ini. Penelitian ini dilakukan di RB Dince, RB Islah, RB Zulfi, RB Rosita dan RB Yossi. Seluruh ibu bersalin yang melakukan yoga kehamilan maupun yang tidak melakukan dengan jumlah 146 orang, dijadikan sebagai populasi. Teknik sampling menggunakan purposive sampling. Kriteria inklusi adalah ibu bersalin dengan kehamilan tunggal, tidak mengalami cacat fisik, sedangkan kriteria eksklusi adalah ibu bersalin dengan komplikasi kehamilan seperti perdarahan, hipertensi, preeklamsi, dll. Jumlah ibu hamil yang melakukan yoga ibu hamil di 5 rumah bersalin ada 51 orang, dengan mempertimbangkan adanya kemungkinan ibu hamil yang melakukan yoga kehamilan tidak dapat dijadikan responden karena termasuk dalam kriteria eksklusi, maka jumlahkelompok intervensi adalah sebanyak jumlah ibu hamil dengan syarat kriteria inklusi terpenuhi dan jumlah kelompok kontrol sama dengan jumlah kelompok intervensi. Alat pengumpulan data kuesioner Zung-Self Rating Scale (ZSRS) dan kuesioner lama persalinan kala I. Analisa Data dilakukan secara Univariat dan Bivariat dengan menggunakan perhitungan Chi Square.

\section{HASIL DAN PEMBAHASAN}

Analisis Univariat

Tabel 1

Distibusi Frekuensi Responden Berdasarkan, Umur, Paritas, Pendidikan dan Pekerjan Responden Di Kota Pekanbaru tahun 2020

\begin{tabular}{llcc}
\hline No. & \multicolumn{1}{c}{ Umur } & Frekuensi & Persentasi (\%) \\
\hline 1 & Usia reproduksi muda (<20 tahun) & 0 & $0 \%$ \\
2 & Usia reproduksi Sehat (20-35 tahun) & 84 & $87,5 \%$ \\
3 & Usia reproduksi Tua (>35 tahun ) & 12 & $12,5 \%$ \\
& Jumlah & $\mathbf{9 6}$ & $\mathbf{1 0 0 \%}$ \\
\hline & Paritas & Frekuensi & Presentasi \\
\hline 1 & Primipara & 33 & $34,4 \%$ \\
2 & Multipara & 63 & $65,6 \% \%$ \\
& Jumlah & $\mathbf{9 6}$ & $\mathbf{1 0 0 \%}$ \\
\hline & Pendidikan & Frekuensi & Presentasi \\
\hline
\end{tabular}




\begin{tabular}{clcc} 
1. & Dasar & 16 & $16,7 \%$ \\
\hline 2. & Menengah & 67 & $69,8 \%$ \\
\hline 3. & Tinggi & 13 & $13,5 \%$ \\
& Jumlah & $\mathbf{9 6}$ & $\mathbf{1 0 0 \%}$ \\
\hline & Pekerjaan & Frekuensi & Presentasi \\
\hline 1. & Bekerja & 21 & $21,9 \%$ \\
2. & Tidak Bekerja & 75 & $78,1 \%$ \\
\hline & Jumlah & $\mathbf{9 6}$ & $\mathbf{1 0 0 \%}$ \\
\hline
\end{tabular}

Berdasarkan tabel 1 orang $(65,6 \%)$, mayoritas pendidikan mayoritas umur responden adalah responden adalah menengah sebanyak berada pada rentang usia reproduksi 67 orang $(69,8 \%)$ dan mayoritas yang aman yaitu sebanyak 84 orang pekerjaan responden adalah tidak $(87,5 \%)$, mayoritas paritas responden bekerja sebanyak 75 orang $(78,1 \%)$ adalah multipara yaitu sebanyak 63

Tabel 1.2

Distribusi Frekuensi Responden Berdasarkan Pelaksanaan Yoga Kehamilan Di Kota Pekanbaru tahun 2020

\begin{tabular}{llll}
\hline No & Yoga Kehamilan & Frekuensi & Presentasi (\%) \\
\hline 1. & Mengikuti yoga & 48 & $50 \%$ \\
2. & Tidak mengikuti yoga & 48 & $50 \%$ \\
\hline & Jumlah & 96 & $100 \%$ \\
\hline
\end{tabular}

Berdasarkan tabel 1.2 Jumlah responden yang mengikuti dan tidak mengikuti senam yoga adalah sama, masing-masing sebanyak 48 orang $(50 \%)$.

Tabel 1.3

Distribusi Frekuensi Responden Berdasarkan Kecemasan dalam Persalinan Di Kota Pekanbaru tahun 2020

\begin{tabular}{llll}
\hline No & Status Kecemasan & Frekuensi & Presentasi (\%) \\
\hline 1. & Cemas & 25 & $26,0 \%$ \\
2. & Tidak Cemas & 71 & $74,0 \%$ \\
\hline & Jumlah & 96 & $100 \%$ \\
\hline
\end{tabular}

\begin{tabular}{crrrrr}
\multicolumn{2}{c}{ Berdasarkan } & tabel & 1.3 & & responden adalah tidak cemas \\
mayoritas & status & kecemasan & & sebanyak 71 orang $(74,0 \%)$.
\end{tabular}


Tabel 1.4

Distribusi Frekuensi Responden Berdasarkan Lama Kala I Persalinan Di Kota Pekanbaru tahun 2020

\begin{tabular}{llll}
\hline No & Status Kecemasan & Frekuensi & Presentasi (\%) \\
\hline 1. & Lama > 6 jam & 40 & $41,7 \%$ \\
2. & Normal <6 jam & 56 & $58,3 \%$ \\
\hline & Jumlah & 96 & $100 \%$ \\
\hline
\end{tabular}

Berdasarkan tabel 1.4 mayoritas normal yaitu sebanyak 56 orang lama kala I persalinan adalah $(58,3 \%)$.

\section{Analisa Bivariat}

Tabel 1.5

Hasil Uji Chi Square Yoga Kehamilan dengan Status Kecemasan Responden Saat Melahirkan Di Kota Pekanbaru Tahun 2020

\begin{tabular}{|c|c|c|c|c|c|c|c|}
\hline \multirow{3}{*}{ Senam Yoga } & \multicolumn{6}{|c|}{ Kecemasan } & \multirow[t]{3}{*}{ P value } \\
\hline & \multicolumn{2}{|c|}{ Tidak cemas } & \multicolumn{2}{|c|}{ Cemas } & \multicolumn{2}{|c|}{ Total } & \\
\hline & $\mathbf{n}$ & $\%$ & $\mathbf{n}$ & $\%$ & $n$ & $\%$ & \\
\hline Yoga & 43 & 60,6 & 5 & 20 & 48 & 50 & 0,000 \\
\hline Tidak yoga & 28 & 39,4 & 20 & 80 & 48 & 50 & \\
\hline Total & 71 & 100 & 25 & 100 & 96 & 100 & \\
\hline
\end{tabular}

Hasil analisis bivariat menunjukkan bahwa mayoritas responden yang rutin mengikuti senam yoga kehamilan mayoritas mengalami tidak cemas yaitu sebanyak 43 orang $(60,6 \%)$ dibandingkan dengan responden yang tidak mengikuti senam yoga kehamilan yaitu 28 orang $(35,8 \%)$. Sedangkan responden yang tidak mengikuti senam yoga mengalami cemas yaitu sebanyak 20 orang $(80,0 \%)$ dibandingkan dengan responden yang mengikuti senam yoga kehamilan yaitu 5 orang $(20,0 \%)$. Uji statistik Chi-square menunjukkan nilai $p$ value $0,000<0,05$ dengan CI 95\%, dengan demikian dapat diambil kesimpulan bahwa terdapat hubungan antara status kecemasan dengan senam yoga kehamilan, dimana tingkat kecemasan ibu pada persalinan kala I dapat berkurang karena pengaruh senam yoga.

Tabel 1.6

Hasil Uji Chi Square Yoga Kehamilan dengan Lama Kala I Persalinan Di Kota Pekanbaru Tahun 2020

\begin{tabular}{|c|c|c|c|c|c|c|c|}
\hline \multirow{3}{*}{ Senam Yoga } & \multicolumn{6}{|c|}{ Lama Kala I } & \multirow[t]{3}{*}{ Pvalue } \\
\hline & \multicolumn{2}{|c|}{$\begin{array}{c}\text { Normal }<=6 \\
\text { jam }\end{array}$} & \multicolumn{2}{|c|}{ Lama > 6 jam } & \multicolumn{2}{|c|}{ Total } & \\
\hline & $\mathbf{n}$ & $\%$ & $\mathbf{n}$ & $\%$ & $\mathbf{n}$ & $\%$ & \\
\hline Yoga & 34 & 60,7 & 14 & 35 & 48 & 50 & 0,013 \\
\hline Tidak yoga & 22 & 39,3 & 26 & 65 & 48 & 50 & \\
\hline Total & 56 & 100 & 40 & 100 & 96 & 100 & \\
\hline
\end{tabular}


yaitu sebanyak 34 orang $(60,7 \%)$ dan responden yang tidak mengikuti senam yoga kehamilan yaitu 22 orang $(39,3 \%)$. Sedangkan responden yang lama kala I > 6 jam mayoritas tidak melaksanan senam yoga sebanyak 26 orang (65\%)

\section{a. Pengaruh Yoga Kehamilan dengan Status Kecemasan Saat Melahirkan Di Kota Pekanbaru}

Hasil penelitian menunjukkan bahwa mayoritas responden yang rutin mengikuti senam yoga kehamilan mayoritas mengalami tidak cemas yaitu sebanyak 43 orang $(60,6 \%)$ dan responden yang tidak mengikuti senam yoga mayoritas mengalami cemas yaitu sebanyak $80,0 \%$. Hasil uji statistik Chi-square juga menunjukkan nilai $p$ value $0,000<0,05$ dengan CI 95\%, dengan arti terdapat pengaruh antara status kecemasan dengan senam yoga kehamilan. Dimana tingkat kecemasan ibu dalam menghadapi persalinan kala I dapat berkurang karena pengaruh senam yoga selama kehamilan.

Hal wajar apabila setiap manusia pernah dialami kecemasan. Kecemasan merupakan suatu perasaan saat seseorang merasa ketakutan atau kehilangan kepercayaan diri yang tidak jelas asal maupun wujudnya yang sifatnya umum[7]. Hampir setiap orang pada waktu tertentu dalam kehidupannya dapat merasakan kecemasan dan ini merupakan reaksi normal terhadap situasi yang sangat menekan kehidupan seseorang. Gejala kecemasan bisa muncul sendiri atau bergabung dengan gejala-gejala lain dari berbagai gangguan emosi [8].

Menurut Varney (2001) dalam Date dkk (2017) menyebutkan, kecemasan yang timbul dapat disebabkan karena dua faktor yaitu antara kesenangan dan rasa nyeri yang sedang dirasakan.Salah satu bentuknya adalah ansietas primer yang timbul karena responden yang mengikuti senam yoga kehamilan yaitu 14 orang $(35,0 \%)$. Uji statistik Chi-square menunjukkan nilai $p$ Yoga, yoga juga meningkatkan kualitas hidup, self efficacy pada persalinan, value $0,013<0,05$ dengan CI 95\%, dengan demikian dapat disimpulkan bahwa terdapat hubungan lama kala I persalinan dengan senam yoga kehamilan, dimana senam yoga dapat memperpendek lama persalinan kala I fase aktif. tauma kelahiran (birth trauma), yang merupakan dasar bagi timbulnya neurotic anxiety. Salah satu bentuknya adalah free-floating anxiety yaitu suatu keadaan cemas dimana individu selalu menantikan kemungkinan yang buruk. Akibatnya ia akan selalu berada dalam keadaan cemas karena takut menghadapi akibat buruk dalam situasi yang tidak menentu [9].

Apabila ibu yang mengalami stress, akan terjadi pelepasan hormone stress akibat sinyal yang berjalan lewat HipothalamicPituitary-Adrenal (HPA) dan berakibat terjadi vasokonstriksi sistematik, dan juga terjadi kontriksi vaso utero plasenta yang berdampak pada aliran darah di dalam Rahim tergangu, sehingga berpengaruh pada penyampaian oksigen (O2) kedalam miometrium. Kejadian tersebut menyebabkan makin lamanya proses persalinan (partus lama) sehingga janin dapat mengalami fetal distress. Stress akibat kecemasan menghadapi persalinan tidak hanya berakibat pada ibu dan juga berdampak pada janin [10]. Kecemasan selama kehamilan, maka dapat dikurangi dengan rutin melakukan senam Yoga [11]. Senam yang mengolah tubuh, pikiran dan mental yang dapat membantu ibu hamil melenturkan persendian dan menenangkan pikiran terutama dalam trimester III merupakan bagian dari senam yoga. Yoga tidak hanya bermanfaat pada kebugaran fisik, tetapi juga mental karena latihan yoga mengajarkan cara bernafas dalam secara sadar dan rileks. Latihan ini akan membantu ibu hamil menghadapi persalinan [3]. Stres dapat diturunkan dengan rutin melakukan 
hubungan interpersonal, fungsi sistem saraf otonom, memberi rasa nyaman, mengurangi atau menurunkan nyeri persalinan dan memperpendek durasi persalinan [4].

Hasil penelitian Mulyati dan Zafariyana (2018) dengan judul Pengaruh Prenatal Yoga Terhadap Kecemasan Dalam Menghadapi Persalinan Pada Primigravida Trimester III Di Jamsin Mq Medika Kota Bandung Tahun 2018 sama dengan hasil penelitian ini. Hasil yang didapatkan adalah Hasil uji pengaruh ( $u j i$ wilcoxon) $p$-value sebesar 0,000 $<0,05$, artinya kecemasan dalam menghadapi persalinan dipengaruhi prenatal yoga. Prenatal yoga sangat bermanfaat untuk mengurangi kecemasan yang dialami oleh ibu hamil dalam menghadapi persalinan. Hal ini sesuai dengan hasil penelitian bahwa kecemasan dalam menghadapi persalinan dipengaruhi oleh prenatal yoga [5].

\section{b. Pengaruh Yoga Kehamilan dengan Lama Kala I Persalinan Responden saat Melahirkan}

Hasil penelitian menunjukkan mayoritas responden yang rutin mengikuti senam yoga kehamilan mayoritas mengalami lama kala I persalinan $\leq 6$ jam yaitu sebanyak $60,7 \%$, dan responden yang tidak mengikuti senam yoga mayoritas mengalami lama kala I > 6 jam yaitu sebanyak $65 \%$ dibandingkan dengan responden yang mengikuti senam yoga kehamilan yaitu $35,0 \%$. Analisis bivariat dengan uji statistik Chi-square juga menunjukkan nilai $p$ value $0,013<0,05$ dengan CI 95\%, dengan arti terdapat hubungan antara lama kala I persalinan dengan senam yoga kehamilan, dimana pengaruh senam yoga dapat memperpendek kala I persalinan fase aktif. Persalinan itu unik, butuh waktu berjamjam bahkan berhari-hari untuk fase awal persalinan ini sampai keproses persalinan yang sesungguhnya, pada masa ini ibu mungkin akan merasa capek, lelah, putus asa dan cemas terutama jika prosesnya lama dan menyakitkan[12]. Servik akan mulai menipis dan membuka pada awal dimulainya proses persalinan dan akibat langsung dari kontraksi. Pada persalinan akan terjadi kontraksi uterus yang merupakan kontraksi otot fisiologis yang menimbulkan nyeri pada tubuh dan akan terjadi lebih sering, lebih lama, dan intensitasnya semakin kuat. [10].

Pada umumnya ibu mulai merasakan sakit atau nyeri yang hebat karena kontraksi uterus mulai lebih aktif. Rasa tidak nyaman dan nyeri akan dirasakan oleh wanita seiring kemajuan persalinan. Hal ini merupakan saat yang paling melelahkan dan berat. Dampak dari kontraksi yang semakin lama, kuat, dan sering selama persalinan dapat menimbulkan kecemasan. Sekresi adrenalin akan meningkat akibat dari kecemasan yang dirasakan ibu bersalin kala I. Konstriksi pembuluh darah

merupakan efek adrenalin yang menurunkan distribusi oksigen ke janin. Proses persalinan lama juga dapat terjadi akibat penurunan aliran darah karena melemahnya kontraksi rahim. [13].

Latihan fisik seperti yoga dapat mengurangi kecemasan pada ibu bersalin [14]. Selama kehamilan dan proses persalinan, pelatihan dan penguasaan teknik pernafasan sangat berperan penting. Latihan ini dilakukan selama melakukan yoga. Latihan dasar pernafasan berdampak memperlancar proses persalinan karena yoga berguna untuk berlatih ketegangan, mempercepat sirkulasi darah serta mencukupi kebutuhan oksigen bagi ibu dan janinnya, memperkuat dan mempertahankan elastisitas otot - otot dinding perut, ligamentum, otot-otot dasar pangul dan otot paha bagian dalam. Yoga membantu ibu relaksasi yang dapat mengatasi ketegangan atau rasa sakit pada saat proses persalinan karena relaksasi otot akan mengontrol kontraksi.

Relaksasi juga akan membantu melemaskan otot dasar panggul dapat melatih, menguatkan dan 
mempertahankan elastisitas otot dasar panggul. Otot akan mengendur secara aktif pada saat mengejan sehingga kepala bayi akan keluar dengan mudah, dengan demikian akan memperlancar dalam proses persalinan

[15]. Lama persalinan kala I dapat diperpendek dengan Yoga karena yoga membantu relaksasi organ panggul [11].

Pada penelitian Devi dkk (2017) tentang pengaruh yoga prenatal dan hypnobirthing terhadap proses persalinan kala I pada ibu bersalin di BPM Restu Depok periode Januari-Juni tahun 2017 yang mendapatkan hasil uji statistik mann-whitney terdapat pengaruh antara yoga prenatal dengan proses persalinan kala I nilai $(p$-value $=0,000)$. Hasil penelitian Devi dkk sesuai dengan penelitian ini dimana kesimpulan penelitian ini yaitu terdapat adanya pengaruh antara yoga prenatal terhadap proses persalinan kala I pada ibu bersalin [2].

\section{KESIMPULAN}

Ada pengaruh yoga kehamilan dengan kecemasan lama kala I persalinan responden saat melahirkan. Oleh karena itu perlu dilakukan peningkatan frekuensi pemberian informasi tentang yoga kehamilan dan frekuensi pelaksanaan kelas senam yoga, baik di RB maupun fasilitas kesehatan lainnya.

\section{DAFTAR PUSTAKA}

[1] Yessi Aprilia, "apriliani yessi, bebas takut hamil dan melahirkan.pdf."

Gramedia Pustaka Utama, Jakarta, 2019.

[2] A. Biaggi, S. Conroy, S. Pawlby, and C. M. Pariante, "Identifying the women at risk of antenatal anxiety and depression: A systematic review," J. Affect. Disord., vol. 191, pp. 62-77, 2016.
[3] I. F. Ayuningtyas,

"ayuningtyas, kebidanan

komplementer.pdf."

Pustaka Baru Press, Yogyakarta, 2019.

[4] K. Curtis, A. Weinrib, and J.

Katz,

"Systematic review of yoga for pregnant women: Current status and future directions," Evidencebased Complement. Altern. Med., vol. 2012, 2012.

[5] I. Mulyati and W. Zafariyana, "Pengaruh Prenatal Yoga Terhadap

Kecemasan Dalam Menghadapi Persalinan Pada Primigravida Trimester Iii Di Jamsin Mq Medika

Kota Bandung Tahun 2018," Pros. Pertem. Ilm. Nas. Penelit. Pengabdi. Masy. (PINLITAMAS 1), vol. 1, no. 1, pp. 424-431, 2018.

[6] T. Eni, R. Devi, K.

Sulastriningsih, and E. Tiawaningrum, "pISSN 2477-3441 eISSN 2477-345X PENGARUH YOGA PRENATAL DAN HYPNOBIRTHING TERHADAP PROSES PERSALINAN KALA I PADA IBU BERSALIN DI BPM RESTU DEPOK PERIODE JANUARI-JUNI TAHUN 2017 THE INFLUENCE OF HYPNOBIRTHING AND YOGA ON LABOR PROCESS ON ONE ON MOTHER LABOR," vol. 5, no.

01, pp. 26-32, 2018.

[7] W. Sutarjo, "wiramihardja, pengantar psikologi abnormal.pdf." PT Resika Aditama, Bandung, 2015. 
[8] 6. Ramadiah Savitri, "savitri, melahirkan.pdf." Media Pressindo, kecemasan.pdf." Pustaka Jakarta, 2015.

Populer

Obor, Jakarta, 2015.

[9] N. Ridhani, S. Prastiwi, and T. Nurmaningsih, "Gambaran Tingkat

Kecemasan Ibu Bersalin Yang Akan Menghadapi Sectio Caesarea Di

Rumah Sakit Baptis," Nurs.

News (Meriden)., vol. 2, no. 2, pp. 71-79, 2017.

[10] Y. A. Bayu Irianti, Erda Mutiara Halida, Fitra Duhita, Fitria Prabandari, Novia Yulita, Setiya Hartiningtiyas, "irianti, asuhan kehamilan berbasis bukti.pdf." Sagung Seto., Jakarta, 2015.

[11] N. Alza, "Pengaruh Yoga Terhadap Kecemasan Ibu Hamil Trimester III di Puskesmas Wilayah Kota Yogyakarta," pp. 1-14, 2017.

[12] Manuaba, manuaba 2010, ilmu peny kandungan dan KB.pdf, 2nd ed. Jakarta: Penerbit Buku Kedokteran ECG, 2010.

[13] E. Dewi, "Pengaruh Kombinasi Yoga Prenatal dan Senam Hamil terhadap Perubahan Kadar Kortisol dan Lama Persalinan Kala I," J. Ilm. Bidan, vol. 1, no. 3, pp. 7-13, 2016.

[14] M. Shannon E. Perry, RN, PhD, FAAN, Marilyn J. Hockenberry, PhD, RN-CS, PNP, FAAN, Deitra Leonard Lowdermilk, RNC, PhD, FAAN, David Wilson, MS, RN, C(INC), Kathryn Rhodes Alden, EdD, MSN, RN, IBCLC and Mary Catherine Cashion, RN, BC, "perry 2015, maternal cild nursing care.pdf." Elsevier : Mosby, Canada, 2015.

[15] 13. Irmawati, "irmawati, 2015, tetap tersenyum saat 
